\title{
Palmoplantar Keratoderma with Periodontitis
}

\author{
${ }^{1}$ Ashok Bhansali, ${ }^{2}$ Anuroopa Kishan, ${ }^{3}$ Setu Mathur, ${ }^{4}$ Gunjan Bhansali
}

\begin{abstract}
Palmoplantar keratodermas (PPKs) comprise a heterogeneous group of keratinization disorders with hyperkeratotic thickening of palms and soles. The PPKs are distinguished by their mode of inheritance and by the presence of certain associated clinical features. Periodontitis was reported in association with more than one syndrome characterized by PPK. Knowledge about heterogeneous groups of acquired or hereditary PPK is important, leading to an appropriate diagnosis and corrective therapies in the future. This case report aims at critically reviewing the literature concerned with PPK and its clinical presentation, in addition to other syndromes manifested along with periodontitis.
\end{abstract}

Keywords: Genetic mutation, Heterogeneity, Palmoplantar keratosis, Periodontitis.

How to cite this article: Bhansali A, Kishan A, Mathur S, Bhansali G. Palmoplantar Keratoderma with Periodontitis. J Health Sci Res 2017;8(2):89-92.

Source of support: Nil

Conflict of interest: None

\section{BACKGROUND}

The development of periodontal disease is largely dependent upon a number of factors, namely, the host immune response, the integrity of the tissues, humoral and cellular immunity, and certain endocrine and nutritional factors. Systemic components modify periodontitis chiefly through their action on the normal immune and inflammatory mechanisms. ${ }^{1}$

These alterations are associated with different pathologies and syndromes that generate periodontal disease either as a primary manifestation or by aggravating a preexisting condition attributable to local factors. The

\footnotetext{
${ }^{1,3}$ Assistant Professor, ${ }^{2}$ Reader, ${ }^{4}$ Consultant

${ }^{1}$ Department of Periodontology, Government Dental College Aurangabad, Maharashtra, India

${ }^{2}$ Department of Periodontology, RajaRajeshwari Dental College \& Hospital, Bengaluru, Karnataka, India

${ }^{3}$ Department of Periodontology, Government Dental College Jaipur, Rajasthan, India

${ }^{4}$ Department of Dentistry, Private Practice, Arham Dental Clinic Osmanpura, Aurangabad, Maharashtra, India

Corresponding Author: Anuroopa Kishan, Reader, Department of Periodontology, RajaRajeshwari Dental College \& Hospital Bengaluru, Karnataka, India, Phone: +919986719039, e-mail: anuganaga04@gmail.com
}

effects of a significant number of systemic diseases upon periodontitis are not clear and usually it is difficult to causally link such diseases to periodontitis. Many of the conditions may give rise to a larger prevalence, incidence, or severity of gingivitis and periodontitis. ${ }^{1}$

In the presence of qualitative or quantitative cellular immune alterations, an increased vulnerability to severe periodontitis can be seen in Down's syndrome (trisomy 21), Chediak-Higashi syndrome, and PapillonLefèvre syndrome (PLS) and palmoplantar keratosis. The affected individuals show an increased incidence of periodontal damage similar to that of generalized prepuberal periodontitis. ${ }^{2}$

Palmoplantar keratoderma (PPK) is a characteristic of many acquired and genetic disorders. Inherited conditions usually are identified by their mode of inheritance, phenotype, and associated features because the underlying defect is seldom. The PPK is a heterogeneous group of disorders characterized by thickening or hyperkeratosis of the palmar and plantar skin with or without other associated clinical features. Oral lesions form a principal characteristic feature in many of these conditions as in other syndromes. ${ }^{3}$

In this case report, we critically review the literature concerned with PPK in its typical and atypical clinical presentation, in addition to stressing on the importance of thorough history and medical examination, together with periodontal, dermatologic, and genetic counseling.

\section{CASE REPORT}

A female patient aged 16 years came to the Department of Periodontology, KLE VK Institute of Dental Sciences, Belgaum, India, with a chief complaint of swollen gums and bleeding while brushing since 1 year. She also complained of pain in the gums since 6 months, which was mild in intensity and subsided as the day progressed.

Oral examination showed inflamed erythematous gingiva that bled on probing. Generalized grade II enlargement confining to the marginal and interdental gingiva ${ }^{4}$ was observed (Fig. 1). A plaque index score (Silness \& Loe, $1964)^{5}$ of 2.04 was recorded, which indicated fair to poor plaque control. There was no abnormal mobility detected and a generalized pseudopocket of 4 to $5 \mathrm{~mm}$ was measured. In addition, no hyperkeratinization of the gingiva was noted. Orthopantamograph showed mild generalized bone loss (Fig. 2). Except for 16 and 26 that were extracted 


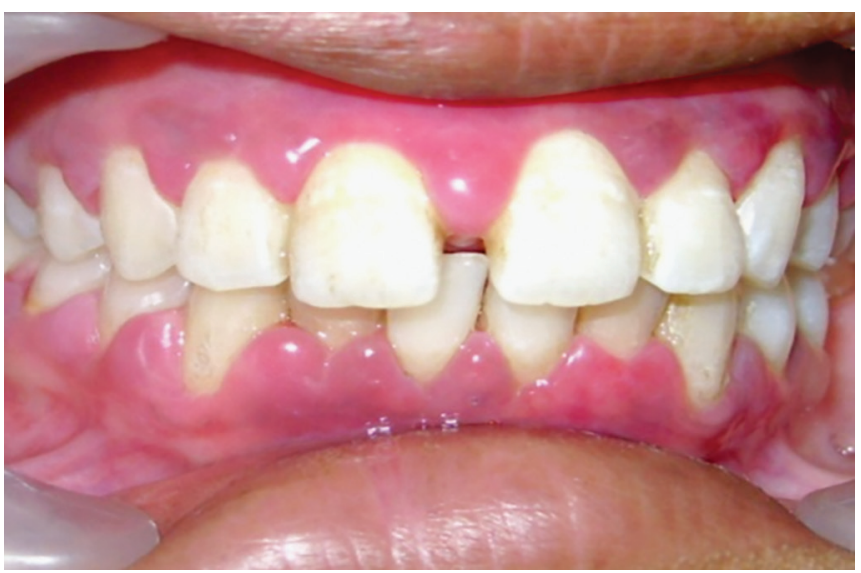

Fig. 1: Preoperative photograph showing grade II enlargement of the gingiva
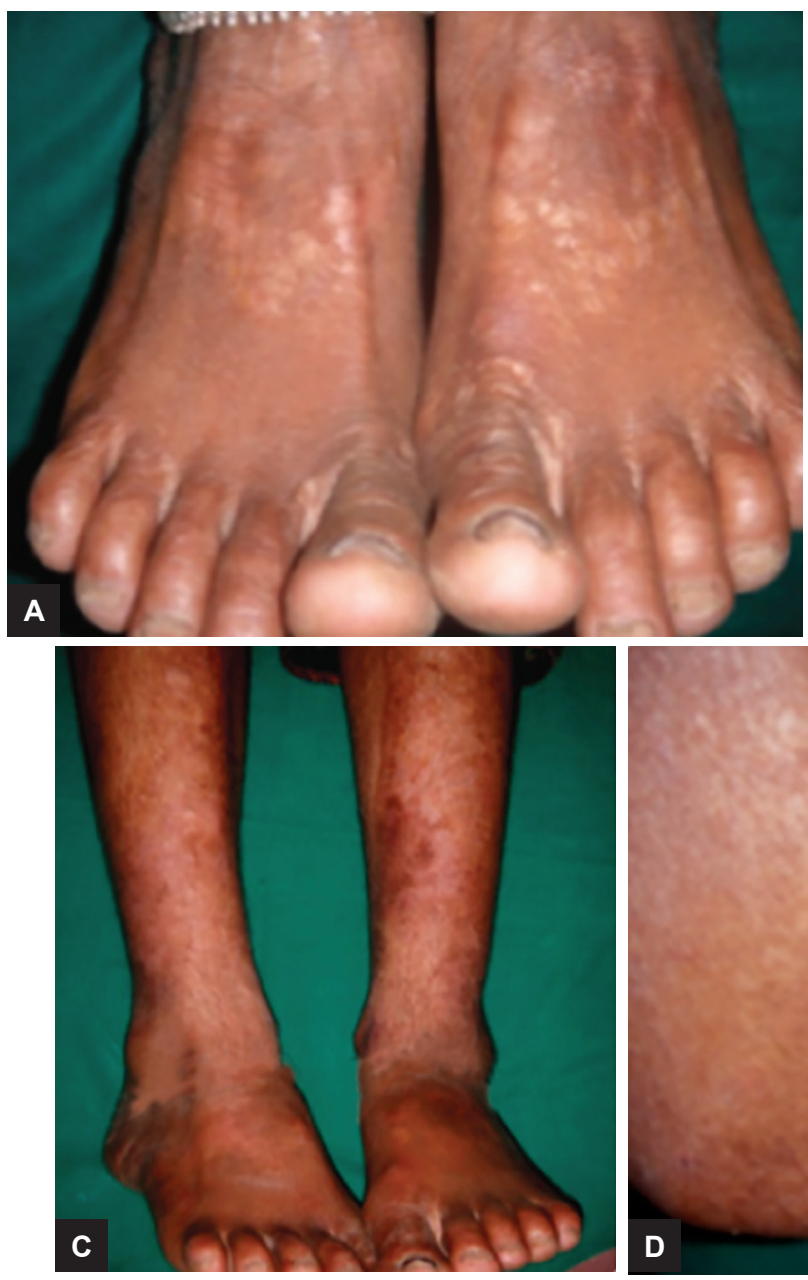

Figs 3A to D: (A) Keratosis and pruritus of feet; (B) Keratosis and pruritus of palm; (C) Keratosis and pruritus of leg; and (D) Keratosis and pruritus of elbow

due to deep caries, all other permanent teeth were present. A $2 \mathrm{~mm}$ diastema was present between the maxillary central incisors. A class II malocclusion was present with increased overbite and overjet.

A complete general and systemic examination revealed hyperkeratosis with pruritus on the palms, leg, and feet. There was no contributing medical history, but
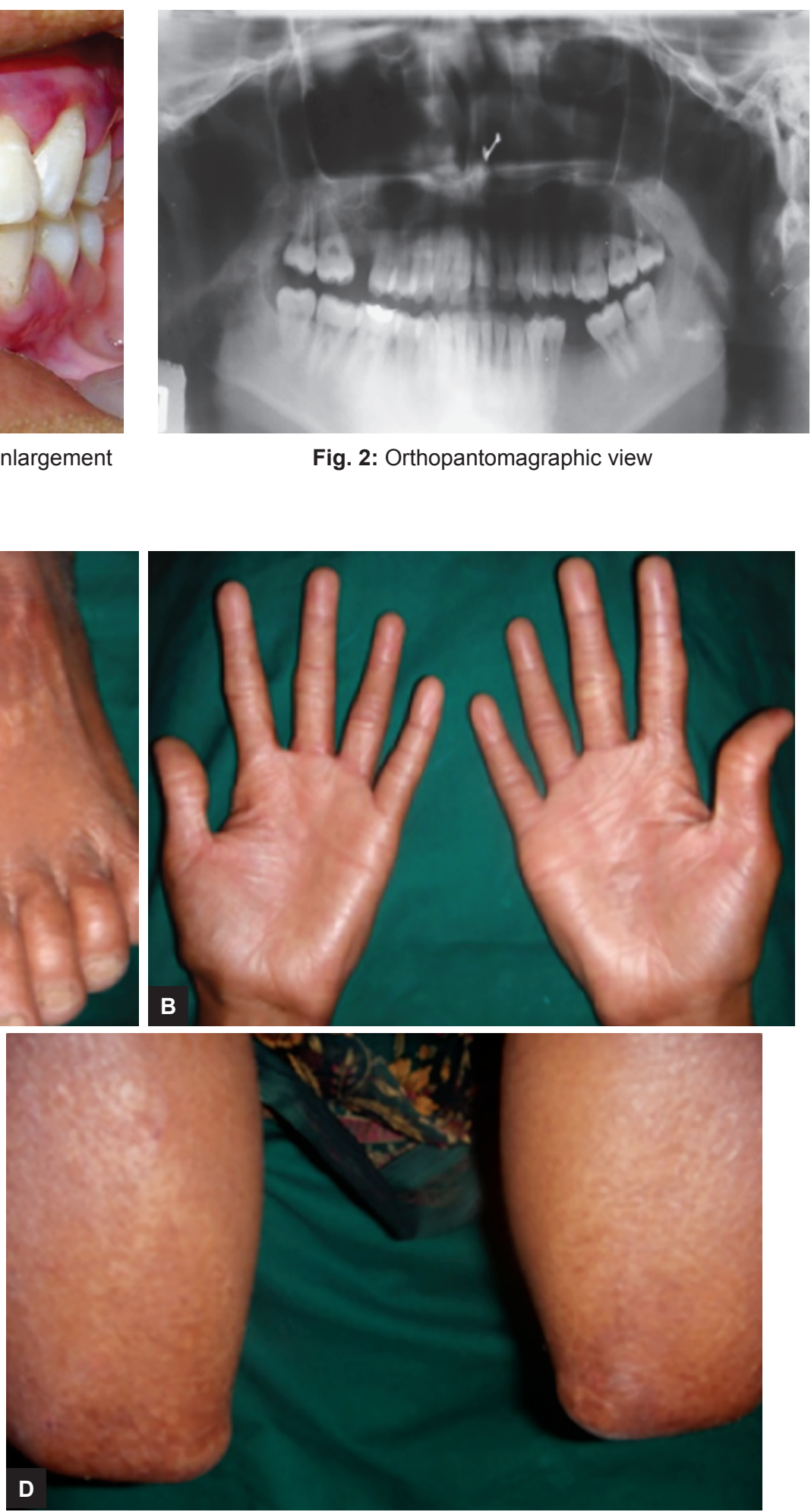

Fig. 2: Orthopantomagraphic view

for the presence of small nodule-like growth, diffuse in nature appearing before the keratosis in these areas, that increased in size and was associated with itching in the elbow and feet (Fig. 3).

Based on the clinical presentation, history, and radiographic findings, a provisional diagnosis of chronic generalized periodontitis associated with PPK was made. 



Figs 4A and B: (A) Immediate postoperative view of maxilla after gingivectomy; and (B) Immediate postoperative view of mandible after gingivectomy

Patient was educated and counseled regarding the condition and sought dermatologic intervention. Intraoral treatment involved routine scaling and root planing (SRP) followed by gingivectomy after 1 week of SRP (Fig. 4). Patient was advised to take antibiotic and analgesics immediately after the procedure and for next 3 days to prevent any postoperative untoward sequelae. Postoperative evaluation 1 week after showed uneventful healing with no adverse reactions. The surgical site exhibited a healthy gingiva with normal consistency and contour during postoperative evaluation at 6 months.

\section{DISCUSSION}

Palmoplantar keratodermas are a diverse group of keratinization disorders presenting as a diffuse or focal thickening of the stratum corneum of palms and soles. It can be caused by a host of dermatological disorders, hereditary or acquired. The heterogeneous nature of this condition is attributed to their symptoms, as well as the type of mutation and affected genes. ${ }^{6}$

The PPK may be divided into acquired and genetic types. Diffuse, focal, and punctuate patterns of palmoplantar keratoderma may be identified distinctly. ${ }^{7}$

Due to the heterogenicity of PPK and the rarity of individual variants, especially certain genetic ones, diagnosis of the disease is complicating. The diagnosis is also challenged by superfluity of causes and mutations in hereditary and acquired PPK, often requiring genetic analysis. The causes of acquired PPK vary, and may include exposure to certain chemicals (e.g., arsenic, chlorinated hydrocarbon fluids), side effects of certain drugs (e.g., beta-glucan, lithium, chemotherapy agents), and metabolic disorders (gravidity, menopause, hypothyroidism, myxedema).

\section{Diagnosis of Palmoplantar Keratoderma}

The clinical appearance of PPK is still the most important criteria for diagnosing PPK. Distinction between diffuse/plane, focal (patchy, striate, filiform, or discoid), or punctuate is made clinically based on how it appears. In addition, the severity of disease, involvement of areas other than the palms or soles, and the onset of other symptoms as part of a syndrome serve as diagnostic aid. The onset of acquired PPK is typically later in life, and it may affect patients who do not have a family history of disease, despite having a corresponding etiology. A thorough history concerning the patient's occupation can aid in diagnosis in such cases. In patients with PPK where the etiology is not clear, the physician should consider the possibility of underlying malignant disease. ${ }^{8}$

Along with the clinical findings, histological characteristics like acanthosis and/or varying degrees of parakeratosis, hyperplasia of the stratum spinosum and granulosum, and perivascular infiltration of inflammatory cells may be helpful in distinguishing between individual entities of PPK. ${ }^{6}$

In case of hereditary PPK, genetic analysis is used to identify the mutated gene, allowing for precise genetic classification. Of late, a number of various genetic mutations have been recognized, which may activate PPK. For instance, aquagenic, nonepidermolytic PPK (Bothnia type) was found to be triggered by dominant mutations in the AQP5 gene (chromosome 12q13), which codes for aquaporin $5 .^{6}$

As discussed earlier, PPK has varied clinical presentations and is one of the commonest manifestations of various genodermal disorders. Though it is associated with Howel-Evans syndrome, keratosis punctata, Vohwinkel's syndrome, Greither's syndrome, periodontitis is not a characteristic feature in these conditions.

It also needs to be differentiated from PLS and HaimMunk syndrome (HMS). But PLS is always associated with early loss of primary and permanent dentition, whereas HMS is an autosomal recessive genodermatological disorder characterized by PPK and periodontitis along with recurrent pyogenic skin infections, acroosteolysis, atrophic changes in nails, arachnodactyly, and 
fingers having tapered phalangeal ends. ${ }^{10} \mathrm{We}$ had to rule out both PLS and HMS as there was no loss of dentition as well as features characteristic of HMS.

In a report by Willet et $\mathrm{al}^{11}$ late onset periodontitis and early onset PPK were noted in patients with PLS. In another report by Bullon et $\mathrm{al}^{12}$ two sisters were found to exhibit early onset PPK and late onset periodontitis. Brown et $\mathrm{al}^{13}$ described three cases having late onset periodontitis as well as skin manifestations. Based on this evidence, the patient needs to be followed up in the future to rule out any of these disorders.

Treatment of oral manifestation of PPK requires an integrated effort from the dermatologist and the dentist. Early treatment along with prophylaxis is essential for the management of periodontitis. Oral retinoids is usually considered as a primary drug of choice for the treatment of keratoderma. In our case, oral isotretinoin (10 mg daily) was administered to the patient for 2 months. The patient showed slow, but definite improvement on follow-up at 6 months. In our case, since there was grade II enlargement, gingivectomy was done. The patient was prescribed appropriate antibiotics with $0.2 \%$ chlorhexidine gluconate mouth rinse and the patient and her family were educated about importance of oral hygiene and the disease condition. Currently, patient is being followed up regularly every 3 months to check the progress of the condition.

\section{CONCLUSION}

Thorough history and medical examination, together with periodontal, dermatologic, and genetic counseling, are important in treating PPK. It is important to distinguish between acquired and hereditary types. In acquired PPK, treatment of the underlying disease or its trigger leads to improvement of symptoms, whereas hereditary forms of PPK are treated only symptomatically. An exact diagnosis is essential for providing targeted corrective therapies to the patient and their family, in order to predict the course of disease and the risk of passing it on. Promising curative therapies are available for PPK. Optimized treatment can lead to a significant improvement in oral and cutaneous symptoms.

\section{CLINICAL SIGNIFICANCE}

Knowledge about PPK and its clinical manifestation is important to help in diagnosis of oral manifestations that gets associated with such conditions. This will help in arriving at a correct diagnosis and providing treatment in a systematic manner.

\section{REFERENCES}

1. Kinane DF, Marshall GJ. Periodontal manifestations of systemic disease. Austr Dent J 2001 Mar;46(1):2-12.

2. Nualart Grollmus ZC, Morales Chávez MC, Silvestre Donat FJ. Periodontal disease associated to systemic genetic disorders. Med Oral Patol Oral Cir Bucal 2007 May 1;12(3):E211-E215.

3. Verma P, Kadam S, Umarji HR, Surya V. Papillon-Lefèvre syndrome in two siblings: a case report. UJMDS 2014;2(2):33-36.

4. Bökenkamp A, Bohnhorst B, Beier C, Albers N, Offner G, Brodehl J. Nifedipine aggravates cyclosporine A-induced gingival hyperplasia. Pediatr Nephrol 1994 Apr;8(2):181-185.

5. Silness J, Loe H. Periodontal disease in pregnancy, II. Correlation between oral, hygiene and periodontal condition. Acta Odont Scand 1964;22:121-135.

6. Schiller S, Seebode C, Hennies HC, Giehl K, Emmert S. Palmoplantar keratoderma (PPK): acquired and genetic causes of a not so rare disease. J Dtsch Dermatol Ges 2014 Sep;12(9):781-788.

7. Freedberg, Irwin M, Fitzpatrick, Thomas B. Fitzpatrick's dermatology in general medicine. 6th ed. New York, NY: McGraw-Hill, Medical Pub. Division; 2003.

8. Patel S, Zirwas M. Acquired palmoplantar keratoderma. Am J Clin Dermatol 2007;8(1):1-11.

9. Kaur B. Papillon Lefevre syndrome: a case report with review. Dentistry 2013;3:156.

10. HartTC,Hart PS, Michalec MD,Zhang Y, FiratliE, Van DykeTE, Stabholz A, Zlotogorski A, Shapira L, Soskolne WA. Haim Munk syndrome and Papillon-Lefèvre syndromes are allelic mutation in cathepsin C. J Med Genet 2000 Feb;37(2): 88-94.

11. Willett LM, Gabriel SA, Kozma C, Bottomley WK. PapillonLefevre: report of a case. J Oral Med 1985 Jan-Mar;40(1):43-45.

12. Bullon P, Pascual A, Fernandez-Novoa MC, Borobio MV, Muniain MA. Late onset of Papillon-Lefevre syndrome? A chromosomic, neutrophic function and microbiologic study. J Clin Periodontol 1993 Oct;20(9):662-667.

13. Brown RS, Hays GI, Flaitz CM, O'Neill PA, Abramovitch K. A possible late onset variation of Papillon Lefevre syndrome: report of 3 cases. J Periodontol 1993 May;64(5):379-386. 